Disorders of the Nervous System

Highlighted Research Paper: Ovarian Cycle Stages Modulate Alzheimer-Related Cognitive and Brain Network Alterations in Female Mice, by Lauren Broestl, Kurtresha Worden, Arturo J. Moreno, Emily J. Davis, Dan Wang, Bayardo Garay, Tanya Singh, Laure Verret, Jorge J. Palop, and Dena B. Dubal

\title{
Estrogen-Dominant Ovarian Cycle Stages Are Associated with Neural Network Dysfunction and Cognitive and Behavioral Deficits in the hAPP-J20 Mouse Model of Alzheimer's Disease
}

\author{
Rosalind S.E. Carney, DPhil
}

Alzheimer's disease (AD) is the most common form of dementia in older adults. In late-onset $A D$, initial symptoms such as memory impairment may first be noticed in individuals in their mid-sixties, whereas symptoms may be observed decades earlier in familial AD (National Institute on Aging, 2017). Seizures and altered neuronal network activity patterns, which may not cause overt cognitive defects, are thought to contribute to early $A D$ pathogenesis in humans (Palop and Mucke, 2016; Vossel et al., 2017; Edwards and Robertson, 2018). Prospective cohort studies have shown that both familial and lateonset AD may be preceded by an asymptomatic preclinical phase that can last for decades. For example, reduced concentrations of amyloid- $\beta(\mathrm{A} \beta)$ in the cerebrospinal fluid and early onset of brain atrophy were found 15 years prior to the onset of AD symptoms (Bateman et al., 2012). Another longitudinal study found that $A \beta$ deposition in the brain can occur over a protracted period of two decades or more (Villemagne et al., 2013). The untreated and significant pathophysiologic damage that occurs during the preclinical phase may explain why several Phase III clinical trials in older individuals with $A D$ have been unsuccessful (Mehta et al., 2017). Without effective early intervention, it is estimated that up to 13 million people in the United States could be affected by AD by 2050 (Brookmeyer et al., 2011). Therefore, it is crucial to look at biological factors that could contribute to pathogenesis at the preclinical stage to delay disease onset and disease progression.

Broestl et al., 2018 hypothesized that the physiology of the female reproductive cycle could contribute to the

Received May 14, 2019; accepted May 14, 2019; First published May 30, 2019. https://doi.org/10.1523/ENEURO.0179-19.2019

This is an open-access article distributed under the terms of the Creative Commons Attribution 4.0 International license, which permits unrestricted use, distribution and reproduction in any medium provided that the original work is properly attributed. preclinical pathogenesis of $A D$ based on the following observations: (1) approximately two-thirds of individuals with $A D$ are female; (2) the preclinical phase of $A D$ likely overlaps with the reproductive life stage of women; (3) neural network dysfunction, such as hyperexcitability, and cognitive defects observed in AD have been linked to $A \beta$ deposition in the brain (Palop and Mucke, 2010); and (4) the two primary ovarian hormones, estrogen and progesterone, can affect neuronal network activity. Estrogen can enhance neural function in non-disease states but increases susceptibly to seizures in mouse models of neurological conditions (Terasawa and Timiras, 1968; Woolley, 2000; Maguire et al, 2005; Ledoux et al. 2009). Conversely, susceptibility to seizures is reduced when progesterone levels predominate (Maguire et al, 2005; Wu et al., 2013). In their eNeuro publication, Broestl and colleagues examined whether the ovarian cycle of the transgenic hAPP-J20 (hAPP) mouse model of AD differs from that of non-transgenic (NTG) mice, and if so, could ovarian cycle alterations contribute to some of the early cognitive defects associated with $A D$ pathogenesis.

The hAPP transgenic mouse expresses a variant form of the human amyloid precursor protein (hAPP) resulting from both the Swedish (K670N/M671L) and Indiana (V717F) mutations associated with familial AD (Mucke et al., 2000). Only female mice, matched by age and genetic background for each experiment and subjected to similar handling protocols, were used in the study; they had not yet developed amyloid plaques. First, the authors confirmed using vaginal cytology that hAPP mice exhibit all four stages of the mouse estrus cycle: proestrus, estrus, metestrus, and diestrus. When ovarian cycling was assessed over a three-week period, hAPP and NTG mice had the same number of estrous cycles of similar duration (each 4-5 d; one estrous cycle was defined as proestrus followed by estrus). However, based on known variations in the estradiol/progesterone ratio $(E / P)$ during the estrous 


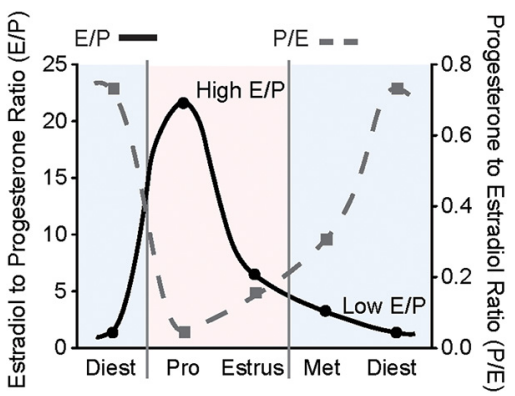

Figure 1. Altered ovarian cycling in female hAPP mice. Estradiol $(\mathrm{pg} / \mathrm{ml})$-to-progesterone $(\mathrm{ng} / \mathrm{ml})$ ratio $(E / P)$ and vice versa $(P / E)$ at each stage of the mouse estrous cycle: diestrus (Diest), proestrus (Pro), estrus, and metestrus (Met). (Adapted from Fig. 1 in Broestl et al., 2018.)

cycle (Walmer et al., 1992), Broestl and colleagues found that, compared to NTG mice, hAPP mice spent more time in the high $E / P$ proestrus and estrus stages versus the low E/P stages of metestrus and diestrus (Fig. 1).

Next, the authors tested whether high or low E/P stages could influence contextual fear memory task using a passive avoidance task. In an additional experimental group, the ovaries were removed (gonadectomized; Gnx) to examine the effects of ovarian hormone depletion in NTG (Gnx NTG) and hAPP (Gnx hAPP) mice. During testing, the latency to enter a dark chamber in which each mouse had received a foot shock $24 \mathrm{~h}$ prior was used as an indicator of contextual fear memory. The ability to learn the task was similar in all mice. However, the reduced latency during testing exhibited by hAPP mice in high E/P stages revealed significant memory defects compared to both hAPP mice in low E/P stages and NTG mice (Fig. 2). No significant statistical differences were found between the latencies of low E/P NTG and low E/P hAPP mice or Gnx NTG and Gnx hAPP mice. These results indicate that elevated levels of estradiol during the ovarian cycle adversely affect cognitive function in hAPP mice.

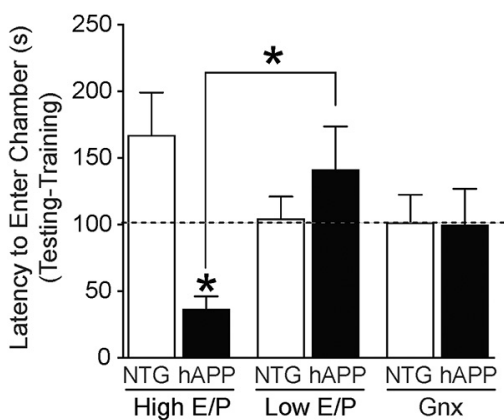

Figure 2. High E/P ovarian cycle stages, proestrus and estrus, worsen fear memory in female hAPP but not NTG mice. Latency (seconds) to enter the dark chamber during testing (minus latency during training) in NTG and hAPP female mice by ovarian status: high E/P (proestrus/estrus), low E/P (metestrus/diestrus), and Gnx NTG and Gnx hAPP mice. Data are mean \pm SEM; * indicates $p<0.05$ versus NTG or as shown by bracket. Dashed line indicates average of $\mathrm{Gnx}$ combined group. (Adapted from Fig. 3 in Broestl et al., 2018.)

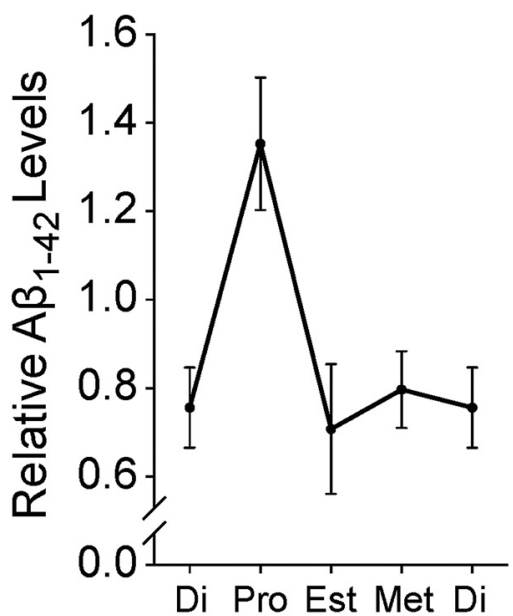

Figure 3. Levels of $A \beta_{1-42}$ surge in the hippocampus of hAPP female mice during proestrus (Pro) compared to the other stages of the ovarian cycle, diestrus (Di), estrus (Est), and metestrus (Met). (Adapted from Fig. 6 in Broestl et al., 2018.)

Broestl and colleagues directly examined whether estrogen increases network hyperexcitability in Gnx mice. Gnx NTG and GNX hAPP mice were injected with a vehicle control or $17 \beta$-estradiol $\left(E_{2}\right)$ to replicate proestrus levels of estradiol. The latency to exhibit signs of seizure, induced $24 \mathrm{~h}$ later by treatment with $\mathrm{GABA}_{\mathrm{A}}$ receptor antagonist pentylenetetrazole, was recorded later; a higher latency indicated increased resistance to seizure. $E_{2}$ treatment led to a reduced latency to reach seizure and heightened seizure severity in Gnx hAPP mice compared to Gnx NTG mice. On the other hand, Gnx NTG and Gnx hAPP mice exhibited similar levels of seizure susceptibility in the vehicle control condition. These results further implicate the role of estrogen in the destabilization of neuronal networks and the hyperexcitability phenotype observed in hAPP mice.

The authors next determined whether $A B$ levels fluctuate during the ovarian cycle in hAPP mice. $A \beta_{1-42}$ levels in the hippocampus of hAPP mice rose significantly during proestrus compared to other ovarian cycle stages (Fig. 3). There was no variation between hAPP mRNA or hAPP protein levels indicating that $A \beta_{1-42}$ levels were affected post-translationally. Previous studies have shown that hyperexcitability affects APP processing and secretion of $A \beta$ into the extracellular space (Kamenetz et al, 2003; Cirrito et al, 2005). Therefore, the estradiol-related increase in network hyperexcitability that occurs during the proestrus stage in hAPP mice could accelerate A $\beta$ production in hAPP mice.

Overall, these results show that hAPP mice exhibit previously unknown alterations in ovarian hormone levels that affect cognitive function. High E/P cycle stages in hAPP mice were associated with memory impairment, increased susceptibility to seizure, and elevated hippocampal levels of $A \beta_{1-42}$. It would be interesting to determine whether women of reproductive age who may develop $A D$ later in life have longer estrogen-dominant ovarian cycle stages, higher plasma $A \beta$ levels, and cog- 
nitive impairments that may correlate with a surge in estradiol levels. Such observations could lead to potential early and even personalized interventions during the preclinical stage of $A D$. In addition, estrogen replacement therapy in post-menopausal women may accelerate pathophysiologic damage in women at risk for developing AD. This study also highlights the importance of reducing sex bias or sex omission in neuroscience research (Will et al., 2017). A recent study showed that firing patterns of hypothalamic gonadotropin-releasing hormone neurons vary according to ovarian cycle status in control mice and a mouse model of temporal lobe epilepsy (Li et al., 2018). Therefore, it may be important to consider ovarian cycle stage during cognitive and behavioral assessment in neurological disease states.

\section{References}

Bateman RJ, Xiong C, Benzinger TL, Fagan AM, Goate A, Fox NC, Marcus DS, Cairns NJ, Xie X, Blazey TM, Holtzman DM, Santacruz A, Buckles V, Oliver A, Moulder K, Aisen PS, Ghetti B, Klunk WE, McDade E, Martins RN, (2012) Clinical and biomarker changes in dominantly inherited Alzheimer's disease. N Engl J Med [Erratum (2012) 367:780 367:795-804.

Broestl L, Worden K, Moreno AJ, Davis EJ, Wang D, Garay B, Singh T, Verret L, Palop JJ, Dubal DB (2018) Ovarian Cycle Stages Modulate Alzheimer-Related Cognitive and Brain Network Alterations in Female Mice eNeuro5:ENEURO.0132-17.2018.

Brookmeyer R, Evans DA, Hebert L, Langa KM, Heeringa SG, Plassman BL, Kukull WA (2011) National estimates of the prevalence of Alzheimer's disease in the United States. Alzheimers Dement 7:61-73.

Cirrito JR, Yamada KA, Finn MB, Sloviter RS, Bales KR, May PC, Schoepp DD, Paul SM, Mennerick S, Holtzman DM (2005) Synaptic activity regulates interstitial fluid amyloid-beta levels in vivo. Neuron 48:913-922.

Edwards M, Robertson NP (2018) Seizures in Alzheimer's disease: is there more beneath the surface? J Neurol 265:226-228.

Kamenetz F, Tomita T, Hsieh H, Seabrook G, Borchelt D, Iwatsubo T, Sisodia S,Malinow R (2003) APP processing and synaptic function. Neuron 37:925-937.

Ledoux VA, Smejkalova T, May RM, Cooke BM, Woolley CS (2009) Estradiol facilitates the release of neuropeptide $Y$ to suppress hippocampus-dependent seizures. J Neurosci 29:1457-1468.
Li J, Robare JA, Gao L, Ghane MA, Flaws JA, Nelson ME, Christian CA (2018) Dynamic and sex-specific changes in gonadotropinreleasing hormone neuron activity and excitability in a mouse model of temporal lobe epilepsy. eNeuro 5.

Maguire JL, Stell BM, Rafizadeh M, Mody I (2005) Ovarian cyclelinked changes in $\mathrm{GABA}(\mathrm{A})$ receptors mediating tonic inhibition alter seizure susceptibility and anxiety. Nat Neurosci 8:797-804.

Mehta D, Jackson R, Paul G, Shi J, Sabbagh M (2017) Why do trials for Alzheimer's disease drugs keep failing? A discontinued drug perspective for 2010-2015. Expert Opin Investig Drugs 26:735739.

Mucke L, Masliah E, Yu GQ, Mallory M, Rockenstein EM, Tatsuno G, $\mathrm{Hu}$ K,Kholodenko D, Johnson-Wood K, McConlogue L (2000) High-level neuronal expression of abeta 1-42 in wild-type human amyloid protein precursor transgenic mice: synaptotoxicity without plaque formation. J Neurosci 20:4050-4058.

National Institute on Aging (2017) What are the signs of Alzheimer's disease? Available at https://www.nia.nih.gov/health/what-aresigns-alzheimers-disease. Retrieved May 1, 2019.

Palop JJ, Mucke L (2016) Network abnormalities and interneuron dysfunction in Alzheimer disease. Nat Rev Neurosci 17:777-792.

Terasawa E, Timiras PS (1968) Electrical activity during the estrous cycle of the rat: cyclic changes in limbic structures. Endocrinology 83:207-216.

Villemagne VL, Burnham S, Bourgeat $\mathrm{P}$, Brown B, Ellis KA, Salvado O, Szoeke C, Macaulay SL, Martins R, Maruff P, Ames D, Rowe CC, Masters CL; Australian Imaging Biomarkers and Lifestyle (AIBL) Research Group (2013) Amyloid $\beta$ deposition, neurodegeneration, and cognitive decline in sporadic Alzheimer's disease: a prospective cohort study. Lancet Neurol 12:357-367.

Vossel KA, Tartaglia MC, Nygaard HB, Zeman AZ, Miller BL (2017) Epileptic activity in Alzheimer's disease: causes and clinical relevance. Lancet Neurol 16:311-322.

Walmer DK, Wrona MA, Hughes CL, Nelson KG (1992) Lactoferrin expression in the mouse reproductive tract during the natural estrous cycle: correlation with circulating estradiol and progesterone. Endocrinology 131:1458-1466.

Will TR, Proaño SB, Thomas AM, Kunz LM, Thompson KC, Ginnari LA, Jones CH, Lucas SC, Reavis EM, Dorris DM, Meitzen J (2017) Problems and progress regarding sex bias and omission in neuroscience research. eNeuro 4.

Woolley CS (2000) Estradiol facilitates kainic acid-induced, but not flurothyl-induced, behavioral seizure activity in adult female rats. Epilepsia 41:510-515.

Wu X, Gangisetty O, Carver CM, Reddy DS (2013) Estrous cycle regulation of extrasynaptic $\delta$-containing $\operatorname{GABA}(\mathrm{A})$ receptormediated tonic inhibition and limbic epileptogenesis. J Pharmacol Exp Therapeut 346:146-160. 